\title{
Presupposition, Perceptional Relativity and Translation Theory
}

\author{
Ayman El-Gamal \\ The Emirates Center for Strategic Studies and Research \\ dr_aymanelgamal@hotmail.com
}

\begin{abstract}
The intertwining of assertions and presuppositions in utterances affects the way a text is perceived in the source language (SL) and the target language (TL). Presuppositions can be thought of as shared assumptions that form the background of the asserted meaning. To translate presuppositions as assertions, or vice versa, can distort the thematic meaning of the SL text and produce a text with a different information structure. Since a good translation is not simply concerned with transferring the propositional content of the SL text, but also its other semantic and pragmatic components, including thematic meaning, a special attention should be accorded to the translation of presupposition. This article examines the intrinsic relation between presupposition and thematic meaning, why the concept is relevant to translation theory, and how presupposition can affect the structure and understanding of discourse. Unshared presuppositions are major obstacles in translation, as cultural concepts may be conveyed through expressions that yield presuppositions. To attain an optimal proximity to the SL text, presupposition needs to be singled out as a distinct aspect of meaning, and distinctions need to be made between definite and indefinite meaning, topic and comment, topic and focus, presupposition and entailment, and presupposition and implicature.
\end{abstract}

\section{Perceptional Relativity}

The notion of figure and ground in Gestalt theory seems to capture the relevance of presupposition to translation theory. According to this school of psychology, the perception 
of a figure in an image is both relative to and influenced by the perception of its background, and vice versa. In Gestalt psychology, the context plays a crucial role in the process of perception, and images are perceived as whole entities rather than the sum of scattered parts. In the same way, an utterance can be perceived in terms of figure and ground, where the figure is the asserted meaning, or, as Levinson (1983: 180) points out, "the main point of what is said, while the ground is the set of presuppositions against which the figure is assessed". The implication of this analogy is that the translation of a particular utterance requires the preservation of the very relativity in which its assertions and presuppositions are perceived in the original. If this perceptional relativity is not maintained in the target language (TL), the translation cannot be judged as accurate.

Few translators would dispute the claim that there is more to a good translation than the mere relay of the propositional content of the source language (SL) text. Apart from fulfilling its basic function of expressing SL propositions, a good translation is also supposed to preserve the relative importance assigned to the different SL information constituents. This generally involves the preservation of the order in which given/new information is presented and the presuppositions imparted in the text as background assumptions. In such a translation, SL information constituents would be perceived in the TL text in their right perspective. The importance of preserving SL presuppositions in the TL text can hardly be exaggerated.

There is also a large consensus that both within and outside a given language, the propositional content of a particular sentence can be expressed in a variety of (quasisynonymous) syntactic structures. Thus the propositional meaning of the English sentences $1 \mathrm{E}, 2 \mathrm{E}$, and $3 \mathrm{E}$ below is more or less the same, and so is the propositional meaning of their respective French counterparts $1 F, 2 F$, and $3 F$.

(1) e. Alfonso wrote this story.

(1) f. Alfonso a écrit cette histoire.

(2) e. It was Alfonso who wrote this story.

(2) f. C'est Alfonso qui a écrit cette histoire.

(3) e. This story was written by Alfonso.

(3) f. Cette histoire a été écrite par Alfonso.

At a deeper level, though, it would not be accurate to translate $1 \mathrm{E}$ into $2 \mathrm{~F}$ or $3 \mathrm{~F}$ despite their apparent propositional similarity. Nor would it be accurate to translate $2 \mathrm{E}$ into $1 \mathrm{~F}$ or $3 \mathrm{~F}$, or $3 \mathrm{E}$ into $1 \mathrm{~F}$ or $2 \mathrm{~F}$. To translate $2 \mathrm{E}$, for example, into $1 \mathrm{~F}$ would necessarily ignore the transfer of the presuppositions imparted by the cleft construction in $2 \mathrm{E}$, namely that some unique entity (Alfonso or any other entity) did in fact write this story. Thus the degree of proximity a translation may have to the original depends in large measure on the accuracy of relaying not only the conceptual/propositional meaning of the SL text, but its thematic meaning as well. Failure to observe the distribution of information in terms of presupposed, given, or new information would result in some loss of meaning and inconsistency with the intentions of the SL text author. 
Presupposition is a crucial element of thematic meaning. It is a highly controversial aspect of non-conceptual meaning that has been contemplated by logicians, philosophers, and linguists since Frege's work on sense and reference in $1892 .{ }^{1}$ The elusiveness of the concept has given rise to many conflicting theories, definitions, and views, and has manifested itself in an extensive literature that is highly technical and plagued with disagreements and sometimes contradictions. Most of the complex and hard-to-solve debates revolve round the defeasibility of presuppositions in certain linguistic and extralinguistic contexts, and what came to be traditionally known as 'the projection problem for presupposition. ${ }^{2}$ Central to this debate is the question of whether to account for the notion in the orderly area of semantics, or in the less orderly speaker-oriented field of pragmatics. Recent work on presupposition suggests that the notion cannot be adequately explained in a purely semantic model, as it fails to explain why some presuppositions 'evaporate' in certain contexts, and why others fail to be inherited by the whole compound sentence. A more viable alternative is provided by pragmatic theory, which places speakers, hearers, and contextual considerations in the core of this relation. Some linguists (e.g. Leech, 1981) argue that the relation is partly logical, and partly pragmatic, noting that the area of presupposition is the area where semantics interacts with pragmatics.

While the concept of presupposition appears to be universal because of its intrinsic connection with such notions as 'shared knowledge' and 'definiteness'. the ways it is expressed in different languages are not. This can obviously be attributed to the peculiarity of the lexical and grammatical systems of individual languages, a peculiarity that makes the concept even more relevant to a linguistic/pragmatic theory of translation. It should be noted, however, that whereas the peculiarity of presupposition-triggers across different languages is relevant and appealing to translation theory, the question of whether the concept belongs to semantics or pragmatics, or why presuppositions evaporate in certain contexts, seems less relevant and appealing. What is perhaps more relevant to translation theory and practice is the identification of the phenomenon itself in source and target languages, and the potential translation techniques that could be used to handle it, and the range of lexemes and structures with which it is bound. These include definite descriptions, factive and counterfactive predicates, implicative verbs, change-of-state verbs, verbs of judging, cleft and pseudo-cleft constructions, comparisons, and some conditional structures. The interrelation between presupposition, thematic meaning, shared knowledge, and given information is quite direct: the thematic presentation of a linguistic message is determined by the presuppositions imparted in this message, and these presuppositions generally reflect the amount of shared knowledge and given information in the context of discourse. According to Givón (1989: 135-136), the sources of presupposed information are the shared situational context, the shared generic context, and the shared discourse context. Failure to translate the concept would normally result in distorting the thematic meaning of the SL text. A similar effect can also result from the addition in the TL text of presuppositions that do not exist in the original. 


\section{Presupposition and the structure of discourse}

Generally discussed under the rubric of given/new information, thematic meaning plays an integral part in the structuring and understanding of discourse. Distinctions associated with this type of meaning include those between given and new information, theme and rheme, topic and comment, topic and focus, and focus and presupposition. Prince (1981: 225) remarks that the general notion of given versus new information appears in the literature under the terms old/new, known/new, and presupposition/focus. The term 'given/new information' is used in analyzing cleft and pseudo-cleft constructions and topicalization, and the way discourses are structured and understood. Prince distinguishes three levels of givenness (ibid., 226-231). One level specifies that the speaker assumes that the hearer can predict or could have predicted that a particular linguistic item will or would occur in a particular position within a sentence. Another level specifies that the speaker assumes that the hearer has or could appropriately have some particular entity in his/her consciousness at the time of hearing the utterance. The third level specifies that the speaker assumes that the hearer knows, assumes, or can infer a particular piece of information, but is not necessarily thinking about it.

Given information has also been defined as information believed by the addressor to be known to the addressee either because it is present in the context, or already mentioned in the discourse. New information, on the other hand, is information the addressor believes to be unknown to the addressee (Brown and Yule, 1983: 154). The term 'given' (information) is used by Clark and Clark (1977: 92) to refer to those presuppositions attributed to clauses within sentences. According to Clark and Clark, a kind of given-new contract exists between speakers and hearers, whereby

the speaker agrees (a) to use given information to refer to information she thinks the listener can uniquely identify from what he already knows and (b) to use new information to refer to information she believes to be true but is not already known to the listener.

According to this contract, a listener can trust that the given information conveys information he/she is able to identify uniquely. Both speaker and addressee understand that given information is information the speaker believes they both agree on, and that the speaker is asserting his/her beliefs about. In this sense the notion of presupposition overlaps with the notion of given information in Clark and Clark's terminology.

As Chafe (1970: 233) remarks, every language is distinctive in the way it represents thematic meaning in its surface structure, and the major role in such representation is played by word order and intonation. Lyons (1977: 510) also argues that languages vary considerably with respect to whether, and how, they grammaticalize differences of thematic structure. These differences, he points out, are "such as to cast doubt upon the possibility of translating even the propositional content of an utterance, both accurately and naturally, from one language into another." For this reason, the translation of thematic meaning requires a heightened awareness of the different tools that could be potentially used to realize this type of meaning in both SL and TL texts. Knowledge of word order and the 
effects of particular lexemes and syntactic patterns in both languages is a prerequisite for that matter.

Discourse is more easily processed when speakers/writers introduce new information with indefinite expressions and subsequently refer to it with definite expressions that normally yield presuppositions. Such definite expressions can be noun phrases or pronominals used anaphorically or exophorically, although definite noun phrases may be used cataphorically to supply new information and existential presuppositions at once. This device is commonly used by novelists in the opening of a narrative as a deviation from the norm to achieve a stylistic effect. In this regard, Hurford and Heasley (1983: 72) remark that the use of definite noun phrases at the beginning of the narrative has the effect of drawing the reader into the narrative fast, "by giving the impression that the writer and reader already share a number of contextual assumptions." A secondary effect of this device is to create a sort of intimacy between the author and the reader so that the information the writer wishes to convey will be more readily accepted by the reader. To maintain this intimacy and false impression about contextual assumptions in a translation, the SL given/new order should be preserved in the TL text, not only in terms of definiteness and indefiniteness, but also in terms of word arrangement. This is especially the case in translation from English into Arabic, or vice versa, since Arabic has a very flexible word order. $^{3}$

The grounds on which speakers make assumptions about what their hearers know or believe can be described in terms of sources of shared knowledge, or in terms of contextual files, such as the generic file, the deictic file, and the text file (Givon, 1989: 207). The generic file refers to the knowledge held in common by all members of the language-culture group. This includes knowledge of the world and the culture, and therefore the shared lexicon. The deictic file has to do with the knowledge shared by speakers and hearers because of their presence together at a speech situation. The text file refers to the knowledge shared by the participants because of what was said earlier in the discourse or in prior text. The generic, text, and deictic sources of definiteness are illustrated in the following examples due to Givón (1989: 207):

(4) "... I got up this morning and the sun was shining..." (Generic).

(5) "... He saw a man and a woman. The woman was tall..." (Text).

(6) "...Take this chair and put it there..." (Deictic).

Some lexemes and structures have been listed in the literature as sources of presuppositions. These will be briefly discussed below, but before we turn to them, some important distinctions need to be made to identify presupposed meaning.

\section{Presupposed versus no-presupposed meaning}

For a translator who wishes to attain maximal proximity to the SL text, the distinction between presupposed and non-presupposed meaning is particularly important. Following 
Leech (1981:289), the distinction can be made at three levels: definite versus indefinite meaning, topic versus comment, and focus versus presupposition. Failure to draw the line between them can easily cause confusion.

Definite expressions are closely linked to existence and reference. They give rise to existential presuppositions, that is, presuppositions that assume the existence of a given referent in some world, whether real, imaginary, fictional, or bypothetical. In saying 'the car won't start'. a speaker conveys the presupposition that some car exists in the world, and can be identified uniquely in the contextual knowledge of both speaker and hearer. In fact, the notion of presupposition was developed in debates about reference, which is simply a relationship between parts of a language and entities that exist (in real or imaginative terns) outside that language.

Definiteness and indefiniteness can be contrasted through the use of definite and indefinite articles. By using a definite article such as the, $l e$, or $e l$, a speaker urges hearer to interpret the referent associated with the article as designating a particular speech situation and a particular assumption. The indefinite article, on the other hand, is a tool to introduce new information. In some languages, the indefinite article occurs after, not before, the noun, as in Classical Arabic, where indefiniteness is expressed with the bound morphemes -on, -an, -in, -oon, or -een. The use of one morpheme rather than another is determined by the position of the noun in the sentence and its grammatical function. For example, -on occurs at the end of a singular noun in a subject position, whereas -een occurs at the end of a plural noun in an object position. In colloquial Arabic, though, indefiniteness is expressed by using no article at all. This is different from languages such as English, French, and Spanish which express indefiniteness with indefinite articles that always precede the noun, such as a/an in English, un/une in French, and uno/una in Spanish. This difference in the article system is worth noting when translating from or into Arabic, especially as it can affect the presuppositional status of an utterance.

Definite expressions include proper nouns, personal pronouns, and noun phrases. A semantic categorization of noun phrases divides them in three subclasses -definite descriptions, indefinite noun phrases, and quantified noun phrases. Definite descriptions are expressions that refer to some definite entity and identify it partly by means of the descriptive content of the expression. As Lyons (1995: 297) points out, definite descriptions may be factorized into two components, descriptive and referential. An example of this is the definite expression my book, where the descriptive component is the word book, and the purely referential component is the possessive $m y$. The referential component $m y$ is nondescriptive, as it does not identify the entity referred to by describing any of its contextindependent properties. The head-noun book, on the other hand, is more or less descriptive of the referent.

Entity-denoting nouns in English fall into different sortal categories according to the essential properties of the classes they refer to. Thus thing is categorially distinguishable from person as the former denotes a class of inanimate entities, whereas the latter denotes a subclass of animate entities of which humans are the prototypical members. Another subclass of noun phrases is that of indefinite expressions, which are context-dependent and 
used with specific reference, such as $a$ woman in $A$ woman wearing sunglasses asked about you. A third subclass is that of quantified noun phrases such as every child, all women, etc. Both the non-descriptive and descriptive components of definite descriptions give rise to two different kinds of presupposition, existential and categorial. In uttering the expression the woman in an ordinary context, a speaker commits himself to two things: the existential presupposition that the referent exists, and the categorial presupposition that the referent is a member of a certain category -in this case, the category of persons. Violation of existential presupposition can be seen in the classic example The king of France is bald, when the referent does not exist. Violation of categorial presupposition can be seen in examples like The Eiffel Tower is clever (Allwood et al., 1977: 150). The categorial presupposition is violated because the predicate be clever presupposes that its subject is something equipped with a mind. As Seuren (1985: 233) points out, the fulfillment of categorial presuppositions is directly checked against a fund of generalized background knowledge. ${ }^{4}$ Speakers need not inspect the world in order to find out if a tower, for example, can be clever, or if a volcano is an animate being so that it can properly be said to be asleep or awake. In this regard, a substantial difference between existential presuppositions and categorial presuppositions is that a text whose existential presuppositions "are not fulfilled can still be a coherent and perfectly intelligible text", whereas "a text with categorial presuppositions unfulfilled will soon become gibberish" (Seuren, 1985: 233).

A second level of distinguishing presupposed from non-presupposed meaning relates to a distinction between topic and comment. Comparing these two notions, Hockett (1958: 201) maintains that topics in English and other familiar languages of Europe are usually subjects and comments predicates. Sentential topic can be roughly defined as the entity about which something is said. It is associated in English with the notion of given information, which generally comes first. Comment, on the other hand, is the statement made about the topic, and is generally associated with new information, which, as Nunan (1993: 45) maintains, comes last "as a rough rule of thumb." Topic is sometimes referred to as the psychological subject, because it does not necessarily coincide with the subject of a sentence. Nor does it have to come first in a sentence, even though it may be the subject, but in unmarked cases the topic usually identifies with the first propositional constituent.

Observing the discourse topic of a text is essential in both shaping and translating a piece of language. At the level of the single sentence, it is also important to observe sentential topic when discourse is created or translated. The relationship between discourse topics and presuppositions is traced by Vennemann (1975: 314) who suggests that there is a general pool of presuppositions which participants resort to and expand as the discourse proceeds. This pool contains information from general knowledge, the context of situation, and the completed part of the discourse. From this presuppositional pool, participants derive propositions about entities whose existence they need not assert. In normal discourse, each participant behaves as if there exists only one presupposition pool shared by all participants. According to Brown and Yule (1983: 80), there is a set of discourse subjects which is part of the general presuppositional pool. Participants who share the assumption that given 
discourse subjects exist do not normally assert their existence. If the participants know each other well, then the number of discourse subjects in a presuppositional pool is likely to be very large.

Distinguishing focus from topic, Dik (1980: 211) states that topic, which marks constituents about which the predication is used to predicate something in the given pragmatic setting, belongs to given information, whereas focus usually marks new information. Topic and focus, however, may overlap, especially in marked cases, when the point of beginning an utterance with a certain constituent is to impart new, rather than given, information. Also, given information may be focused on if there is something new to be said about it, for purposes of emphasis or contrast.

Corresponding to the notion of topic is the formal category of theme, which Brown and Yule (1983: 126) use to refer to "the left-most constituent of the sentence." For each simple sentence, there is a theme which is that part of a sentence which occurs first and can be described as the starting point of the utterance, and a rheme which is everything that follows in the sentence, and which consists in a commentary on the theme, and has the most communicative importance. ${ }^{5}$ Like topic and comment, the terms theme and rheme are used to explain how discourse units are assigned various degrees of importance and arranged to handle given and new information. Thematic elements, as Hatim and Mason (1990: 212 213) remark, are context-dependent, and consequently of lesser communicative importance than context-independent rhematic elements. For Halliday (1970: 161), the theme is a component in the complex notion of a subject a psychological subject similar to "the peg on which the message is hung, the theme being the body of the message. " $\mathrm{He}$ further describes the information structure notions of given and new as often

conflated with theme and rheme under the single heading 'topic and comment'; the latter, however, is (like the traditional notion of 'subject') a complex notion, and the association of theme with given, rheme with new, is subject to the usual 'good reason' principle already referred to - there is freedom of choice, but the theme will be associated with the 'given' and the rheme with the 'new' unless there is good reason for choosing some other alignment (1970: 162).

The notion of theme, as Brown and Yule (1983: 133) remark, has two main functions. First, it connects back and links in to the previous discourse, maintaining a coherent point of view. Second, it serves as a point of departure for the further development of discourse.

Leech (1981:292) considers the topic/comment division conducive to the interpretation of presupposition. Like presupposition, the topic of a sentence has a tendency to be unaffected by negation. This is clearly the case in passive sentences which are equivalent to their active counterparts in terms of conceptual meaning, but different in thematic meaning. For example, sentences like (4) and (5) below are felt to have the same truthvalues, but their negations, (6) and (7), are felt to be slightly different:

(7) The killing of Francis Ferdinand caused the Great War.

(8) The Great War was caused by the killing of Francis Ferdinand. 
(9) The killing of Francis Ferdinand did not cause the Great War.

(10) The Great War was not caused by the killing of Francis Ferdinand.

(11) There was a Great War.

Whereas it is possible to infer (11) from (10), it is not possible to draw the same inference from (9). When a sentence is negated, its comment is negated too, but the topic remains unnegated. In the examples above, (7) entails (11), whereas (8) presupposes it, and the difference between (7) and ( 8 ) is a difference not in conceptual meaning, but in the way the message is presented in terms of word order, focus, presupposition, and thematic meaning. And it is a difference worth observing in translation. The thematic choice of topic has the positive effect of adding emphasis to some aspect of the conceptual message, and the negative effect of suppressing certain possibilities of interpretation, which are implicit in the conceptual meaning.

The term focus is used to refer to the information at the center of the speaker's communicative interest. In this sense, Crystal (1991: 276) remarks, it is opposed to presupposition, which corresponds to what the Prague school has viewed as given information. Lyons (1977: 509) remarks that the terms focus and presupposition relate to aspects of information structure from the point of view that "expressions that convey new information are stressed, and expressions conveying information that the speaker presents as given, or recoverable from context, are unstressed." The term focus typically corresponds to the term rheme, which is used by the Prague school linguists to refer to the expression which contains the information the speaker wishes to communicate.

The notion of focus is useful in drawing the line between presupposition and assertion. Focus is typically achieved through phonology, rather than through syntax or semantics. The focus of information realized through accentuation of a certain syllable can also be realized syntactically through cleft sentences. The phonological and syntactic realization of focus is shown in the examples below, where the sentences are identical in everything except that the focus is different in each sentence:

Phonological and Syntactic Realization of Focus

Phonological Realization

Syntactic Realization

(12) His wife drove to Madrid last JUNE. It was in JUNE that his wife drove to Madrid

(13) His wife drove to MADRID last June. It was to MADRID that his wife drove last June.

(14) His wife DROVE to Madrid last June. It was BY CAR that his wife went to Madrid.

(15) His WIFE drove to Madrid last June. It was his WIFE who drove to Madrid last June

In the sentences above, the element bearing the nucleus is the focus of information, while the remainder of each sentence is the presupposition. The difference between focus and presupposition in (12)-(15) is illustrated below:

Presupposition

(16) His wife went to Madrid at some time $\mathrm{x}$

(17) His wife went to some place $x$ last June
Focus

$\mathrm{x}=$ last June

$\mathrm{x}=$ Madrid 
(18) His wife went by some means $x$ to Madrid last June

$\mathrm{x}=\mathrm{car}$

(19) Some person $x$ drove to Madrid last June

$x=$ his wife

Insofar as (12)-(15) mean the same as their cleft counterparts, they pass the negation test for logical presupposition, and presuppose (16)-(19). In the case of cleft sentences, their presuppositional status can be tested by the fact that their negative sentences have the same presuppositions:

(20) It wasn't to Madrid that his wife drove last June.

The negation of (13) also seems to have the same presupposition:

(21) His wife didn't drive to MADRID last June.

Exploring the intrinsic relation between presuppositions and marked focus, Enkvist (1980: 134-152) distinguishes three kinds of foci-corrective focus, emphatic focus, and information focus. Corrective focus is used by speakers to repair flaws in conversation by repeating the word, and laying a distinctive stress on a particular syllable of the word. Enkvist considers the basic function of focus marking to be the evocation of a presuppositional set, and the presentation of one member of the set as new information. Other functions include the widening of the range of old, shared, and presupposed information. Whether the evocation of the presuppositional set or the presentation of a set member as new information is primary depends on the structure and on the context. Thus, in saying (22)

(22) MARIAN spoke to the manager

with a stress on 'Marian'. a speaker presupposes that his addressee already knows that someone spoke to the manager. The presuppositional set of the focally marked constituent comprises all those values that can be inserted for the corresponding variable 'someone' in the presupposition. The change of focus changes the presuppositional set, as in (23):

(23) Marian SPOKE to the manager.

In this sentence, the presuppositional set consists of all those verbs that express things Marian could have done to the manager, and from among which 'spoke' was selected. Sentence (23) could have been turned into a passive to place the new information, Marian, into the sentence-final position. The reason why a speaker should prefer an active sentence, and mark the focus as in (22), is to evoke a presuppositional set that could not be evoked otherwise. Selecting one member out of a presuppositional set amounts to contrasting it with the other members of the same presuppositional set, and results in conveying new information. 
While the focally marked item carries and pinpoints new information, it increases the range of given information carried by the focally unmarked items in the tone group. This is shown in the following examples, drawn from Enkvist (1980):

(24) The tall girl in blue shorts carried the red ball.

(25) The TALL girl in blue shorts carried the red ball.

(26) The tall girl in BLUE shorts carried the red ball.

In (24), which is focally unmarked, the theme, which presumably consists of shared information, comprises the entire subject noun phrase. In (25), only 'tall' is new information, whereas the existence of more than one girl in blue shorts is presupposed. In (26), only 'blue' is marked as new information, and the existence of more than one tall girl in shorts would be presupposed.

The linear order and the thematic information structure of a sentence is affected by such operations as passivization, topicalization, cleft, there-insertion, dislocation, and extraposition, all of which constraint the choice of focally marked items. Enkvist mentions three mechanisms that regulate the thematic arrangement of the sentence. First, lexical thematizations can be carried out with the aid of lexical converses such as (27) and (28):

(27) Martha sold the guitar to Jane.

(28) Jane bought the guitar from Martha.

Secondly, syntactic thematizations can be achieved through a change in the syntactic pattern, by using a passive for example:

(29) The two ministers attended the meeting.

(30) The meeting was attended by the two ministers.

Thirdly, there are topicalizations or commentizations, which only front or postpone an item without concomitant changes in the syntactic structure, as in (31) and (32):

(31) Fred has written the letter.

(32) The letter Fred has written.

Of the three types of thematic arrangement, topicalizations are the most strongly marked. In a topicalized structure, the fronted element often evokes a presuppositional set recoverable from an earlier part of the text. The final element is strongly rhematic, carrying new information and often linking up with something coming later in the text. 


\section{Presupposition as inference}

Another level of distinction can also be made between presupposition and two other types of inference, namely entailment and implicature, the former considered a fairly central semantic relation, and the latter a purely pragmatic relation.

Entailment, also known as logical implication, is a logical relation that exists between propositions such that for a proposition $p$ to entail a proposition $q$ it is necessary in all worlds in which $p$ is true that $q$ be true. Accordingly, (33) entails (34), but does not presuppose it:

(33) The crocodile killed the deer.

(34) The deer died.

In the example above it is impossible to think of any circumstances in which the first sentence is true and the second false, no matter what the context is.

Entailment is a transitive relation, that is, it applies cumulatively: if $p$ entails $q$, and $q$ entails $r$, therefore $p$ entails $r$.

(35[p]) I saw three men.

(36[q]) I saw two men.

(37[r]) I saw human beings.

Entailment explains how two sentences can be paraphrases of each other. In this case, the two sentences mutually entail each other so that whenever one is true the other must also be true. As a result of this mutual entailment, each of the two sentences has the same set of entailments as the other:

(38) It is easy to learn Spanish.

(39) Spanish is easy to learn.

It has been argued (e.g., Burton-Roberts, 1989: 9-11) that the negation of a proposition $p$ entailing a proposition $q$ destroys the entailment whereas the negation of a proposition $p$ presupposing a proposition $q$ does not affect the presupposition. Thus (40) entails (41), but presupposes (42):

(40) Somebody stole my car.

(41) Somebody stole a vehicle.

(42) I have a car.

Presupposition and entailment have one property in common: both satisfy a conjunction test. If a sentence is conjoined with the negation of its entailment or presupposition, the result is semantic anomaly. In the examples below (43) entails (44) and presupposes (45): 
(43) The rescue team managed to save Lucy

(44) The rescue team saved Lucy.

(45) The rescue team tried to save Lucy.

When (43) is conjoined with the negation of (44) as in (46) or the negation of (45) as in (47), the resulting sentences are anomalous:

(46) !The rescue team managed to save Lucy, but didn't save Lucy.

(47) !The rescue team didn't try to save Lucy, but managed to save Lucy.

Presupposition is also similar to entailment in that it is also a transitive relation. If a proposition $p$ presupposes $q$, and $q$ presupposes $r$, then $p$ presupposes $r$. In the examples below (48) presupposes (49), and (49) presupposes (50). Then (48) presupposes (50):

(48[p]) The King of France is wise.

(49[q]) There exists a king of France.

(50[r]) There exists a country by the name of France.

While entailment is a logical inference carried by propositions and sentences (in the sense of idealized 'grammatical' strings), conversational implicature is a pragmatic inference carried by utterances. The term implicature is used by Grice (1975) to refer to what a speaker can imply, suggest, or mean, as distinct from what he/she literally means. Conversational implicature is based on a pragmatic principle that involves the cooperation of speakers in communication. This 'Cooperative Principle' has four maxims, known as the maxims of Quantity, Quality, Relation, and Manner. The maxim of Quantity provides that sufficient information be given to ensure smooth communication. The maxim of Quality implies that in normal cooperative circumstances, when a speaker asserts something he implicates that he believes it, and when he asks a question he implicates that he sincerely wants an answer, and when he promises to do something he implicates that he intends to do it. The maxim of Relation provides that a speaker's utterance be relevant to the situation at hand. This principle underlies the connectivity of exchanges that might otherwise appear fragmented and disconnected, such as the following example due to Grice (1975):
A: I am out of petrol
$\mathrm{B}$ : There is a garage around the corner.

In this exchange A does not simply describe some state of affairs, but rather makes a request for help. B's answer is cooperative in that it acknowledges the request, and responds positively by stating that there is a garage the corner, opening and selling petrol.

The maxim of Manner provides that speakers be perspicuous, orderly, and brief. Resorting to a different language, jargon, or special words is a discourse strategy to deny the audience access to part, or all, of the meanings of an exchange. ${ }^{7}$ 
Grice (1975:50;57-58) lists six properties of implicature. Apart from the basic property of being inferences carried by utterances, rather than sentences, implicatures exhibit the properties of calculability, defeasibility, non-detachability, non-conventionality, and indeterminacy. The calculability of implicature explains why the essential properties are largely predictable. For an addressee to be able to calculate that a particular conversational implicature is present, he must know, or believe he knows, the conventional or literal meaning or sense of the utterance, and the Cooperative Principle and its maxims. He must also know the context, "linguistic and otherwise of the utterance", other parts of background information, and that this knowledge must be shared with the speaker (Grice, 1975:50). The property of defeasibility, which also applies to presupposition and most pragmatic inferences, means that implicatures can be cancelled by adding to them some additional premises. For example, implicatures can be suspended by if-clauses:

(51) Malak has three cars, if not more.

Implicatures are also directly and overtly deniable without any sense of anomaly:

(52) Robert has three children, in fact ten.

Unlike presupposition, implicature is attached to the semantic content of what is said, not to its linguistic form. This has been referred to in the literature as the non-detachability of implicatures. With the exception of implicatures arising under the maxim of Manner, they cannot be detached from an utterance simply by changing the words of the utterance for synonyms. In the examples below, (53) presupposes (54), whereas (55), which seems to be semantically and truth-conditionally equivalent to (55), does not imply (54):

(53) Betty didn't manage to get to work on time.

(54) Betty tried to get to work on time.

(55) Betty didn't get to work on time.

The importance of this property is that it may serve to distinguish conversational implicatures from other kinds of pragmatic inference such as presupposition and conventional implicatures.

Implicatures are not part of the conventional meaning of linguistic expressions. The fact that a speaker needs to know the literal meaning or sense of a sentence before he can calculate its implicatures in a context implies that the implicatures cannot be part of that meaning. This property also follows from the fact that an utterance can be true while its implicature is false, and vice versa as in the example below:

(56) Patrick hit Fred,

which by Quantity would implicate (57): 
(57) Patrick didn't kill Fred by hitting him.

If it were a fact that Patrick had killed Fred, a speaker, in saying just (56), would be violating the cooperative principle, and more specifically, the maxim of Quantity by withholding information. A speaker attempting to mislead might say (56) in a situation where (56) is true but (57) false.

The indeterminacy of implicatures means that an expression with a single meaning can yield different implications on different occasions. Even on one specific occasion, the set of associated implicatures may not be exactly determinable. Many implicatures can arise from (58):

(58) William is a machine.

As Levinson (1983: 118) points out, an utterance like (58) could convey that William is cold, or efficient, or never stops working, or puffs and blows, or has little in the way of grey matter, or indeed any and all of these. So implicatures can have a certain indeterminacy in at least some cases, incompatible with the stable determinate senses usually assumed in semantic theories.

\section{Sources of presupposition}

Presuppositions seem to be associated with certain words and structures. These are listed in the literature by philosophers such as Frege (1892/1952) and Sellars (1954), and linguists such as Fillmore (1969), Kiparsky and Kiparsky (1971), Karttunen (1971), and others. Presupposition can result from the use of definite expressions, factive predicates, implicative verbs, change-of-state verbs, iteratives, verbs of judging, temporal clauses, cleft structures, comparisons, nonrestrictive relative clauses, counterfactual conditionals, and interrogative sentences.

Presupposition is closely linked with the notion of definiteness, which involves the speaker's assumptions about the hearer's beliefs. A definite expression is a noun phrase that a speaker uses to convey the assumption that his addressee will be able to identify its referent, usually because it is the only thing of its kind in the context of the utterance, or because it is unique in the universe of discourse. The three main types of definite noun phrases in English are proper names, phrases introduced by a definite determiner, and personal pronouns. ${ }^{8}$ Lyons (1995: 67) points out to the non-universality, "not just of the definite article, but also of anything that might be called a semantic category of definiteness, in natural languages. " Definite expressions yield existential presuppositions, as in (59):

(59) The fish is in the fridge,

where the speaker presupposes the existence of some fish and some fridge that the hearer can uniquely identify in the context of discourse. 
Presuppositions can also be induced by factive predicates (see Kiparsky and Kiparsky, 1971: 345-369). These are predicates which Allwood et al. (1977: 150) point out, "express properties or relations involving facts." The list of factive predicates includes regret, aware, realize, odd, know, be sorry, be proud, be indifferent, be glad, be sad, and be astonishing. Green (1989:71) remarks that one kind of factive presuppositions is associated with expressions that take a sentential subject or object. The object complements of epistemic factives such as know and realize are presupposed as true propositions, and so are the subject complements of such predicates as prove and be obvious. Emotive factives such as regret, amaze, astonish, and be surprised also presuppose the truth of their complements:

(60) Kathy regretted that her husband was careless.

Presupposition: Kathy's husband was careless.

A wrong translation of the factive verb would not yield the factive presupposition induced in the original.

Presuppositions can also be triggered by change-of-state verbs. These are verbs whose lexical meaning denotes a change of state, and therefore they presuppose that some state of affairs used to exist but no longer does. The verb die, for instance, denotes the end of a life of a certain living entity, and therefore presupposes that the subject of the verb was alive before. Such verbs include stop, begin, continue, start, finish, carry on, cease, take, leave, enter, come, go, and arrive:

(61) He stopped smoking.

Presupposition: He used to smoke.

Iterative predicates also give rise to presuppositions. Iteratives are lexical items which have a property of repetitiveness among their features. Examples of iteratives include again, anymore, another_time, call_back, restore, and repeat:

(62) The police arrested him again.

Presupposition: The police arrested him before.

Verbs such as accuse, blame, and criticize are said to presuppose that the complement did something "wrong" in some way at least from the speaker's viewpoint (Fillmore, 1969: 121-22). It has been argued that the implications carried by such verbs are not presuppositional, as "they are not attributed to the speaker, so much as to the subject of the verb of judging" (Levinson, 1983: 182):

(63) The president was accused of lying to the people.

Presupposition: Lying to the people is "bad" from the speaker's point of view. 
Implicative verbs also give rise to presuppositions. The notion of implicative verbs was introduced by Karttunen (1971) in a study of some predicates that carry along the presupposition that the infinitive complements express true propositions. Just as Kiparsky and Kiparsky (1971) distinguish predicates which presuppose the truth of their complements from those which do not, Karttunen (1971: 340-358) also makes an equally important distinction among predicates that take infinitive complements. In the Kiparskys' system, the predicates which presuppose the truth of their complements are termed factive, while those which are not accompanied by similar presuppositions are called non-factive. In Karttunen's study, the classes of predicates he singles out are labeled implicative and non-implicative depending on their presuppositional properties. His list of implicative predicates includes manage, remember, bother, get, dare, care, venture, condescend, happen, be careful, have the misfortune, take the time, take the opportunity, take the trouble, and take it upon oneself. Non-implicative predicates include agree, decide, want, hope, promise, plan, intend, try, be likely, be eager, be ready, and have in mind. Implicative predicates are similar to factive predicates in that the truth of the affirmative main sentence implies the truth of the complement. For example, the truth of (64), which involves an implicative verb, implies the truth of (65):

(64) John managed to open the door.

(65) John opened the door.

Structural presuppositions fall in various categories. One type of structural presupposition is induced by adverbial clauses, including temporal clauses introduced by such time markers as before, while, since, and as. The example given by Frege (1892/1952: 71) about the separation of Schleswig-Holstein from Denmark is a classic example of presuppositions introduced by such temporal markers as after:

(66) "After the separation of Schleswig-Holstein from Denmark, Prussia and Austria quarrelled."

Frege (1892/1952: 71) states that it is "sufficiently clear that the sense is not to be taken as having as a part the thought that Schleswig-Holstein was once separated from Denmark. But that this is the necessary presupposition in order for the expression "After the separation of Schleswig-Holstein from Denmark' to have any reference at all".

Another type of structural presupposition closely bound with focus and information structure is induced by cleft and pseudo-cleft constructions. As noted above, cleft and pseudo-cleft constructions provide classic examples of the way topics and foci are handled in marked ways to affect the distribution of given/new information and impart presuppositions. Through clefts, speakers place focus on the element that follows be. Pseudo-cleft sentences also carry a presupposition in the part that follows what so that it is taken for granted. ${ }^{9}$ Widdowson (1978: 35) remarks that the effect of clefts is to separate out given information and place it parenthetically within the subordinate clause. In clefts, the 
new information appears in a prominent and contrastive position at the end of the main clause. In written English, where intonation is absent, the cleft construction marks the information focus. As Quirk and Greenbaum (1973: 415) state, the highlighted element has the full implication of the contrastive focus, and the rest of the clause is considered as given information. The presupposition of a cleft sentence can be identified with a proposition formed by taking the material after the relative marker who, or that, and inserting a variable or indefinite existential expression like somebody, or something that agrees in number and gender with the item in focus position. A cleft sentence is one which begins with the prop subject $i t$ and verb to be. This string is followed by an element of the clause moved to the initial position. The rest of the clause is then introduced by the relative pronoun who or that:

(67) It was his wife who reported him to the police.

Presupposition: Somebody reported him.

A pseudo-cleft sentence is one that begins with what and ends with a noun phrase, for the purpose of focusing attention on the noun phrase.

(68) What made him mad was that his wife reported him to the police. Presupposition: Something made him mad.

Both cleft and pseudo-cleft constructions seem to convey the further presupposition that the focal element is the only element to which the predicates apply. But, as Prince (1978: 883906) shows, the two clefts perform different pragmatic functions and cannot be interchangeable. The presuppositions arising from cleft and pseudo-cleft constructions seem also to arise from heavy stress on some constituent, as exemplified in (69):

(69) This rumor was/wasn't circulated by JIM,

where the presupposition of the implicit cleft with the stressed constituent is that someone circulated this rumor.

Presuppositions are induced by comparisons and contrasts. These may be marked by particles like too, back, in return, or comparative constructions. The occurrence of back in (70) presupposes that the subject was responding to a call:

(70) I called him back.

Presuppositions can also be triggered by nonrestrictive relative clauses, which provide additional parenthetical information (Keenan, 1971: 47). ${ }^{10}$ These clauses are so called because they do not restrict the meaning of the noun phrases they modify. The view that such clauses give rise to presupposition is based on the claim that they are not affected by the negation of the main verb outside the relative clause. An example of this clause is (71) below: 
(71) President Sadat, who signed a peace treaty with Israel, was assassinated in 1981.

Counterfactual conditionals induce a type of presupposition called counterfactual presupposition in which what is presupposed is contrary to facts. The conditional structure in (72) carries the presupposition that the information in the if-clause is not true:

(72) If Mary had come ten minutes earlier, she would have seen James.

Presupposition: Mary had not come ten minutes earlier.

Counterfactual presuppositions can also be triggered by such counterfactive verbs as pretend and wish:

(73) Alice pretended she was sick.

Presupposition: Alice was not sick.

(74) Maurice wished he had been born rich"

Presupposition: Maurice was not born rich.

Presuppositions are also carried by questions. This fact has been used in arguments favoring the handling of presupposition outside the sphere of logical semantics, since questions are not propositions that logic can deal with (Leech, 1981:280). The presuppositions carried by questions are somewhat different from the existential presuppositions associated with the use of definite referring expressions. The question in (75) below presupposes that something happened to the coalition. This presupposition does not remain constant under negation:

(75) What happened to the coalition?

The negation of (75) would make the presupposition, not that something happened to the coalition, but rather that there is something that did not happen to it.

Different interrogative forms elicit different presuppositions. Katz (1972:211) maintains that yes/no questions generally have vacuous presuppositions, being the disjunctions of their possible answers. These are the only kinds of presuppositions of questions that are constant under negation. Alternative questions presuppose the disjunction of their answers:

(76) Do you intend to come or are you just saying that to evade me?

Wh-questions introduce the presuppositions obtained by replacing the Wh-word by the appropriated existentially quantified variable, for example, who: by someone; where: by somewhere; how: by somehow. Such presuppositions are not constant under negation.

(77) Why did they come so early?

Presupposition: They came early for some reason. 
Adverbs also constitute sources of presuppositions.

(78) Betty moved/didn't move quickly to her room.

Presupposition: Betty moved to her room.

\section{Presupposition, shared cultural assumptions, and translation}

Contextual considerations and shared knowledge appear to be inextricable components of most definitions of presupposition. Thus Fromkin and Rodman (1983: 189) define presuppositions as explicit assumptions made by the speakers about the real world, and according to them, the sense of an utterance may depend on these assumptions. For Yule (1985: 100), a presupposition is "what a speaker assumes is true or is known by the hearer". In another work, he defines presupposition as "something the speaker assumes to be the case prior to making an utterance" (1996: 25). Discussing the role of context in the interpretation of discourse, Brown and Yule (1983:23) adopt the view that presupposition is "defined in terms of assumptions that the speaker makes about what the hearer is likely to accept without challenge." Levinson's definition of presupposition is based on mutual knowledge and appropriacy: "An utterance $A$ pragmatically presupposes a proposition $B$ iff $A$ is appropriate only if $B$ is mutually known by participants" (1983: 205). Leech's definition also places the speaker at the heart of the relation: "In saying $X$ the speaker s purports to take for granted the truth of $Y^{\prime \prime}(1981: 287)$.

The claim that cultural differences and unshared presuppositions are major obstacles in translation is not especially controversial. Malinowski's experience with the Trobrianders is a classic example. Malinowski (1923: 299-300) considers the unification of cuitural context a prerequisite for translation. In fact, his famous theory of context of situation was influenced by the question of the translation of untranslatable words. In his ethnography of the Trobriand Islands, a small group of islands to the east of New Guinea, Malinowski illustrates the problem of translation by giving indigenous texts taken from native Trobrianders, followed by word-for-word translations. One problem he has to cope with in the translation is that English does not have acceptable equivalents to indigenous words. For him, the reason lies in the wide gap between the Western European culture of his readers and the Trobriand culture. Even when English equivalents of native words were acceptable, their intelligibility was in question.

The lexical and syntactic structures of a language, with which presuppositions are bound, cannot be separated from the culture of which this language is part. ${ }^{11}$ Commenting on this intertwining between language and its natural cultural context, McLendon (1977. 153) argues that "real sentences in real languages naturally occur almost uniquely in discourse contexts, and considering sentences extracted from their natural contexts necessarily risks excluding information pertinent to understanding their true meaning and function." 
Languages are distinctive in the way they express the cultures with which they are integrated, and they segment reality in individual ways. It is through their unique systems of distinctive sounds, morphemes, and longer linguistic structures that they express culturespecific concepts of customs, objects, and institutions. ${ }^{12}$ Given this fact, cultural relativity has been considered a source of translation difficulties (see for example Hudson, 1980: 85). This is not especially controversial. Culture, according to one definition, is "the way of life and its manifestations that are peculiar to a community that uses a particular language as its means of expression" (Newmark, 1995: 94). Since meanings can be expressed in one language and not in others, one would expect cultural specificity to have a significant bearing on the theory and practice of translation.. To circumvent such problems, translators may adopt various techniques including the use of new forms to express the meaning in question, the use of SL words in transliterated forms, unpacking SL cultural words, or sometimes sacrificing the words that are deemed unimportant. The extent to which presuppositions associated with cultural words are lost or preserved in the translation may depend on the translator's own assessment of the amount of meaning presuppositions contribute to the text. Judging whether the SL presuppositions add little or nothing to the TL context, or whether they cause, rather than solve, comprehension problems, translators may opt for doing away with them.

Concepts peculiar to a certain culture may be expressed by means of definite noun phrases which carry existential presuppositions. They may also be denoted with lexical items that carry lexical presuppositions. If such concepts do not exist in the TL culture, the SL presuppositions are likely to be lost in the translation, and the whole context may be affected, as contexts expand with the addition of more presuppositions, and communication may be rendered less successful. ${ }^{13}$.

One difficulty translators usually face is the handling of shared assumptions and presuppositions, and judging the extent to which a given presupposition is really required for the TL readership. As Cook (1989: 90) points out, the underestimation of shared assumptions in discourse makes it boring, while an overestimation of it makes it incomprehensible.

The claim that the unification of cultural context makes translation an easier task (Malinowsky, 1923: 299-300; Robins, 1980: 24) underlies the general agreement that prefect translation between languages is impossible. The ideal of total equivalence is very much dubious, and has even been described as a chimera (Bell, 1991: 6). Translating the whole communicative value of a language requires the translation of all the semantic and pragmatic values carried by the socio-semantic system of that language. The more types of meaning a translation can maintain (for example, conceptual, thematic, connotative, social, affective, reflected, and collocative), the closer it is to an "ideal" translation.

As shown above, words and syntactic structures carry presuppositions. If these words and structures are distinctive of a certain cultures, the presuppositions will also be unique to that culture. In addition, if pragmatic presuppositions are defined in terms of shared assumptions, mutual knowledge, and contextual appropriacy, then they make direct reference to culture for their interpretation. In other words, what is presupposed in a culture 
need not be presupposed in another. Mey (1993: 298) remarks that "cultural presuppositions can be major stumbling-blocks on the road to understanding" across different cultures. Intercultural misunderstanding may result because participants do not share cultural presuppositions, as in the exchange below which Mey $(1993: 299)$ had with a Japanese temple attendant:

Tourist: Is there a toilet around here?

Attendant: You want to use?

Tourist (somewhat astonished): Sure I do.

Attendant: Go down the steps.

According to Mey, the highly unexpected back-channel question 'You want to use?' was made because the pragmatic presuppositions in the Japanese culture are clearly different from his own. One possible reason the attendant asked the question was to find out whether the tourist's question could have anything to do with the different kinds of toilets (Japanese, Western) that are now available in Japan. Misunderstanding cultural presuppositions may also result in mistranslation, or at least, cause translation problems.

\section{Conclusion}

Presupposition is a pragmatic inference that is intrinsically linked to thematic meaning, shared knowledge, and given information, and has a significant role to play in the translation of thematic meaning, and assigning the same values of prominence given to information constituents in the SL text. Failure to translate it results in distorting the thematic meaning of the SL text, and so does the addition in the TL text of presuppositions that do not exist in the original. The more the translation preserves the status of figure and ground of an utterance, the more faithful and accurate it is.

Presupposition is a type of inference that can be confused with entailment or implicature, which are also types of inference connected with the use of certain forms of language. Each, however, has its own distinctive properties. Presupposition differs from entailment in that it is essentially a property of utterances that disappears in certain linguistic contexts, and certain linguistic structures. Entailment is a purely logical concept concerned with propositions, and is not affected by the context. Implicature is a pragmatic contextdependent concept based on cooperative dynamics among speakers. A careful choice of the lexemes and structures that yield this particular inference in the TL text would therefore ensure that the resulting inference is presupposition, rather than entailment or implicature.

The concept of presupposition is not confined to a particular language, but the ways it is realized differ from one language to another, hence its relevance to a linguistic theory of translation. Presupposition is a pragmatic inference triggered by certain lexemes and structures, which include definite descriptions, factive and counterfactive predicates, implicative verbs, change-of-state verbs, and verbs of judging. The structures which trigger 
presuppositions comprise cleft and pseudo-cleft constructions, extrapositions, and some conditionals and adverbial clauses. An accurate and economic translation of thematic meaning cannot be achieved unless the SL presuppositions are relayed in the TL text. This is possible through the use of the appropriate structures and lexical items that give rise to this inference and achieve the same pragmatic effect. This is more likely to happen in a semantic translation that lays more emphasis on authorship than readership. In this translation method, presuppositions are more likely to be perceived as background assumptions differing from assertions, and carrying the same relative importance assigned to them in the original.

\section{Notes}

1. The relation between reference and presupposition is detailed in Frege Uber Sinn und Bedeutung, translated as 'On Sense and Reference' in Geach and Black (1952). Frege's views were refuted by Russell (1905), but advocated by Strawson $(1950 ; 1952)$. The notion has been intriguing to linguists for the last thirty years or so.

2. The projection problem for presuppositions refers to the particular problem of how presuppositions of component sentences behave when these components are part of complex and compound sentences. Consider for example: (a) Sally does not regret buying a Mercedes, and (b) Sally does not regret buying a Mercedes, because in fact she never bought one. The presupposition induced by the factive verb regret in (a) fails to be inherited in the compound sentence (b). Presupposition also disappears in certain contexts. In the example Sue died before she finished the thesis, the proposition that Sue finished the thesis is not presupposed, as it contrasts our basic. beliefs and knowledge of the world, namely that people do not do things when they die. The presupposition, however, would hold in Sue cried before she finished the thesis. Here non-linguistic factors affect the survival of presuppositions.

3. In written Arabic, subjects, objects, and verbs can come in initial, medial, or final positions. Special suffixes indicate the status of the part of speech. In spoken Arabic, however, utterances generally begin with subjects, and in cases when subjects are omitted, the verb form indicates the subject, as in Spanish soy, which indicates that the subject is I.

4. In written Arabic, subjects, objects, and verbs can come in initial, medial, or final positions. Special suffixes indicate the status of the part of speech.

5. The term rheme goes back to the Greek word rhema, that is, what is said.

6. The question of violating categorial presuppositions has received little attention in the presuppositional literature compared to the violation of existential presupposition like the one involved in the famous example The king of France is bald. This can be perhaps traced to the fact that the violation of categorial presupposition, unlike the violation of existential presupposition, can be accounted for as being anomalous within the framework of sentence-based semantics.

7. For Halliday, the subject is a complex of four distinct functions which coincide unless there is some reason for them not to do so. Three of these functions lie in the structure of the clause and the fourth lies in the structure of the information unit. These are (1) the actor, which is a logical subject; (2) the modal subject, or the grammatical subject; (3) the theme which is a psychological subject and finally (4) given information, which is another psychological subject that relates to the textual aspect of language. For more details see Halliday (1970, pp. 140-165). 
8. Arabic belongs to the vast majority of languages which, as Lyons (1995: 67) points out, do not have a separate word-form which can be identified grammatically and semantically with the English definite article.

9. The effects produced by the passive, cleft constructions and extraposed sentences, and other syntactic structures are treated by Jacobs and Rosenbaum (1971) in terms of transformational theory, together with the processes whereby deep structures are transformed into surface structures that contribute a special effect to style.

10. Green (1989: 85) opposes the view that sentences with nonrestrictive clauses presuppose the truth of the relative clause, indicating that "all analysts agree that in fact nonrestrictive relative clauses are asserted rather than presupposed. " Commenting on the example "Taylor, who has a 42inch vertical leap, will be a sophomore next year", Green says the rational speaker of the utterance does not take it for granted that the addressee realizes that Taylor has a 42-inch vertical leap. "Instead", she adds, "the nonrestrictive clause . . offers a way of asserting that information, while not making it the main point of his utterance."

11. To cope with translation difficulties arising from cultural differences, Newmark (1995: 94103) suggests that the solution to such problems depends not so much on the collocations of linguistic or situational context as on the readership and on the setting. Among the procedures he suggests are deletion of redundant stretches of language in non-authoritative texts, such as metaphors and intensifiers, adopting paraphrases, glossaries, notes, transference, naturalization and literal translation.

12. As Lyons (1977: 248) remarks, every language is integrated with the culture in which it operates, and its lexical structure reflects those distinctions which are important in the culture.

13. Successful communication, Cook (1989: 91) remarks, involves the transfer of information, which "presupposes a successful evaluation of what is known or not known at the outset."

\section{References}

Allwood, Jens, Lars-Gunnar Andersson, and Östen Dahl (1977): Logic in Linguistics. Cambridge: Cambridge University Press.

Bell, Roger T. (1991): Translation and Translating. Theory and Practice. London: Longman.

Brown, Gillian and George Yule (1983): Discourse Analysis. Cambridge: Cambridge University Press.

Burton-Roberts, Noel (1989) : The Limits to Debate. A Revised theory of Semantic Presupposition. Cambridge: Cambridge University Press.

Chafe, Wallace L. (1970) : Meaning and the Structure of Language. Chicago: The University of Chicago Press.

Clark, H. H. and Clark, E. V. (1977): Psychology and Language. New York: Harcourt, Brace, Jovanovich.

Cole, Peter (ed.)(1981): Radical Pragmatics. New York: Academic Press.

Cole, Peter and J.L. Morgan (eds.)(1975): Syntax and Semantics. Vol. 3. Speech Acts. New York: Academic Press.

Cook, G. (1989): Discourse. Oxford: Oxford University Press.

Crystal, David (1991): A First Dictionary of Linguistics and Phonetics. ( $3^{\text {rd }}$ ed.). Oxford: Blackwell.

Dik, Simon C. (1980): Studies in Functional Grammar. London: Academic Press. 
El-Gamal, Ayman (2000): Preserving Presupposition in the English Translation of Naguib Mahfouz's Midaq Alley, Miramar, and Fountain and Tomb. Unpublished Doctoral Dissertation, Cairo: Ain Shams University.

Enkvist, Nils Erik (1980): "Marked focus: function and constraints". In Greenbaum, Sidney et al., eds., Studies in English Linguistics for Randolph Quirk. London: Longman, 134-152.

Fillmore, Charles. J. (1969). "Types of lexical information". In F. Kiefer, ed., Studies in Syntax and Semantics. Dordrecht and Boston: D. Reidel Publishing Company, 109-137.

Charles J. Fillmore, and D. Terence Langendoen (eds)(1971): Studies in Linguistic Semantics. New York: Holt, Rinehart \& Winston.

Frege, Gottlob (1952): "On sense and reference". In P.T. Geach and M. Black, eds., Translations from the Philosophical Writings of Gottlob Frege. Oxford: Blackwell, 56-78. (Original work published 1892).

Fromkin, Victoria and Robert Rodman (1983): Introduction to Language (3rd ed.). New York: Holt, Rinehart \& Winston.

Givón, Talmy (1989): Mind, Code and Context. Essays in Pragmatics. New Jersey and London: Lawrence Erlbaum Associates.

Green, Georgia M. (1989): Pragmatics and Natural language Understanding. New Jersey and London: Lawrence Erlbaum Associates.

Greenbaum, Sidney, Geoffrey Leech, and Jan Svartvik (eds.)(1980): Studies in English Linguistics for Randolph Quirk . London: Longman.

Grice, H. Paul (1975): "Logic and Conversation". In P. Cole and J.L. Morgan, eds., Syntax and Semantics: Vol. 3. Speech Acts. New York: Academic Press, 41-58.

Halliday, Michael A. K. (1970): "Language structure and language function". In J. Lyons, ed,, New Horizons in Linguistics. Harmondsworth: Penguin Books, 140-165.

Hatim, Basil and Ian Mason (1990): Discourse and the Translator. London: Longman.

Hockett, Charles F. (1958): A Course in Modern Linguistics. New York: Macmillan.

Hudson, R. A. (1980): Sociolinguistics. Cambridge: Cambridge University Press.

Hurford, James R. and Brendan Heasley (1983): Semantics. A Coursebook. Cambridge: Cambridge University Press.

Jacobs, Roderick A. and Peter S. Rosenbaum (1971): Transformations, Style, and Meaning. Waltham, Massachusetts and Toronto: Xerox College Publishing.

Karttunen, Lauri (1971) : "Implicative verbs". Language 47(2): 340-358.

Katz, Jerrold J. (1972): Semantic Theory. New York: Harper and Row.

Keenan, E. L. (1971): "Two kinds of presupposition in natural language". In C.J. Fillmore and D. T. Langendoen, eds., Studies in Linguistic Semantics. New York: Holt, Rinehart \& Winston, $45-54$.

Kiefer, F. (ed.) (1969): Studies in Syntax and Semantics. Dordrecht and Boston: D. Reidel Publishing Company.

Kiparsky, P, \& Kiparsky, C. (1971): "Fact". In Danny D. Steinberg, and L.A. Jacobovits, eds., Semantics. An Interdisciplinary Reader in Philosophy, Linguistics and Psychology. Cambridge: Cambridge University Press, 345-369.

Leech. Geoffrey (1981): Semantics (2nd ed.). Harmondsworth: Penguin Books.

Levinson, Stephen C. (1983): Pragmatics. Cambridge: Cambridge University Press.

Lyons, John (1977): Semantics, 2 vols. Cambridge: Cambridge University Press. 
Lyons, John (1995): Linguistic Semantics: An Introduction. Cambridge: Cambridge University Press.

Malinowski, B. (1923): "The problem of meaning in primitive languages". In C.K. Ogden and L.A. Richards, eds., The Meaning of Meaning. London: Routledge, 296-336.

McLendon, Sally (1977): "Cultural presupposition and discourse analysis". In M. Saville-Troike, ed., Georgetown University Round Table on Languages and Linguistics 1977. Washington, D.C.: Georgetown University Press, 153-189.

Mey, Jacob L. (1993): Pragmatics: An Introduction. Oxford: Blackwell.

Newmark, Peter (1995): A Textbook of Translation. New York: Phoenix ELT.

Nunan, David (1993): Introducing Discourse Analysis. Harmondsworth: Penguin Books.

Oh, C. \& Dinneen, D. (eds.)(1979): Syntax and Semantics. Vol. 11:Presupposition. New York: Academic Press.

Prince, Ellen F. (1981) : "Towards a taxonomy of given-new information". In Peter Cole, ed., Radical Pragmatics. New York: Academic Press, 223-253.

Prince, E. F. (1978): "A comparison of wh-clefts and it-clefts in discourse". Language 54(4): 883-906.

Randolph Quirk and Sidney Greenbaum (1973): A University Grammar of English. London : Longman.

Robins, R. H. (1980). General Linguistics. An Introductory Survey (3rd ed.). London and New York: Longman.

Russell, Bertrand (1905): "On denoting". Mind 14: 479-483.

Sellars, W. (1954): "Presupposing". Philosophical Review 63: 197-215.

Seuren, Pieter A. M. (1985): Discourse Semantics. Oxford: Blackwell.

Steinberg, Danny D., and L. A. Jacobovits (eds.)(1971): Semantics. An Interdisciplinary Reader in Philosophy, Linguistics and Psychology. Cambridge: Cambridge University Press.

Strawson, Peter F. (1950): "On referring". Mind 59: 320-344.

Strawson, Peter F. (1952): Introduction to Logical Theory. London:Methuen.

Vennemann, T. (1975): "Topic, sentence accent, and ellipsis: a proposal for their formal treatment". In E.L. Keenan, ed., Formal Semantics of Natural Language. Cambridge: Cambridge University Press.

Widdowson, H. G. (1978): Teaching Language as Communication. Oxford University Press. Yule, George (1985): The Study of Language. Cambridge: Cambridge University Press. Yule, George (1996): Pragmatics. Oxford University Press. 